\title{
Review
}

\section{International Society of Urological Pathology (ISUP) Consensus Conference on Handling and Staging of Radical Prostatectomy Specimens. Working group 2: T2 substaging and prostate cancer volume}

Theo H van der Kwast ${ }^{1}$, Mahul B Amin², Athanase Billis ${ }^{3}$, Jonathan I Epstein ${ }^{4}$, David Griffiths ${ }^{5}$, Peter A Humphrey ${ }^{6}$, Rodolfo Montironi ${ }^{7}$, Thomas M Wheeler ${ }^{8}$, John R Srigley ${ }^{9}$, Lars Egevad ${ }^{10}$, Brett Delahunt ${ }^{11}$ and the ISUP Prostate Cancer Group*

${ }^{1}$ Department of Pathology, University Health Network and University of Toronto, Toronto, ON, Canada; ${ }^{2}$ Department of Pathology and Laboratory Medicine, Cedars-Sinai Medical Center, Los Angeles, CA, USA; ${ }^{3}$ Department of Pathology, School of Medicine, State University of Campinas (Unicamp), Campinas, Brazil; ${ }^{4}$ Department of Pathology, Johns Hopkins Hospital, Baltimore, MD, USA; ${ }^{5}$ Department of Pathology, Cardiff University School of Medicine, University Hospital of Wales, Cardiff, UK; ${ }^{6}$ Department of Pathology and Immunology, Washington University School of Medicine, St Louis, MO, USA; ${ }^{7}$ IFCAP, Section of Pathological Anatomy, Polytechnic University of the Marche Region, School of Medicine, United Hospitals, Ancona, Italy; ${ }^{8}$ Department of Pathology, Baylor College of Medicine, Houston, TX, USA; ${ }^{9}$ Department of Pathology and Molecular Medicine, McMaster University, Hamilton, ON, Canada; ${ }^{10}$ Department of OncologyPathology, Karolinska Institutet, Stockholm, Sweden and ${ }^{11}$ Department of Pathology \& Molecular Medicine, Wellington School of Medicine and Health Sciences, University of Otago, Wellington, New Zealand

The 2009 International Society of Urological Pathology consensus conference in Boston made recommendations regarding the standardization of pathology reporting of radical prostatectomy specimens. Issues relating to the substaging of pT2 prostate cancers according to the TNM 2002/2010 system, reporting of tumor size/ volume and zonal location of prostate cancers were coordinated by working group 2 . A survey circulated before the consensus conference demonstrated that $74 \%$ of the 157 participants considered pT2 substaging of prostate cancer to be of clinical and/or academic relevance. The survey also revealed a considerable variation in the frequency of reporting of $\mathrm{pT} 2 \mathrm{~b}$ substage prostate cancer, which was likely a consequence of the variable methodologies used to distinguish pT2a from pT2b tumors. Overview of the literature indicates that current pT2 substaging criteria lack clinical relevance and the majority $(65.5 \%)$ of conference attendees wished to discontinue pT2 substaging. Therefore, the consensus was that reporting of pT2 substages should, at present, be optional. Several studies have shown that prostate cancer volume is significantly correlated with other clinicopathological features, including Gleason score and extraprostatic extension of tumor; however, most studies fail to demonstrate this to have prognostic significance on multivariate analysis. Consensus was reached with regard to the reporting of some quantitative measure of the volume of tumor in a prostatectomy specimen, without prescribing a specific methodology. Incorporation of the zonal and/or anterior location of the

Correspondence: Dr TH van der Kwast, Department of Pathology, University Health Network, 11th floor, 200 Elizabeth Street, Toronto, Canada M5G 2C4.

E-mail: theo.vdkwast@uhn.on.ca

*See Appendix 1 for members of the ISUP Prostate Cancer Group.

Received 29 October 2009; revised 13 July 2010; accepted 14 July 2010; published online 3 September 2010 
dominant/index tumor in the pathology report was accepted by most participants, but a formal definition of the identifying features of the dominant/index tumor remained undecided.

Modern Pathology (2011) 24, 16-25; doi:10.1038/modpathol.2010.156; published online 3 September 2010

Keywords: adenocarcinoma; prostate; tumor stage; tumor volume

Compared with those of the prostate-specific antigen (PSA) screening era, contemporary prostatectomy series have shown a sharp increase in the proportion of organ-confined (pT2) prostate cancers, and these constitute a great majority of cases reported in Europe and North America. ${ }^{1}$ Within category pT2 prostate cancers, a wide variation in tumor extent may be seen, which varies from single microscopic lesions to large volume multifocal tumors, often involving both sides of the prostate. This heterogeneity of tumor volume of pT2 prostate cancers and the potential impact on prognostic assessment has resulted in attempts to subcategorize organ-confined tumors. To date, few publications have addressed the prognostic impact of each of the defined pT2 substages, while most evaluate the prognostic impact of biomarkers in relation to an aggregated pT2 category, and with pT3a/pT3b cancers. In the recently released TNM 2010 staging system, ${ }^{2}$ the clinical and pathological substaging of pT2 prostate cancers has been retained, although the prognostic value of this has been questioned..$^{3,4}$

The standard reporting of prostate cancer volume/ size remains a contentious issue. In particular the controversy has been fuelled by the concerns of many pathologists that the introduction of timeconsuming and elaborate methodologies for assessing tumor volume would add little to outcome assessment in individual cases of prostate cancer, while contributing significantly to an ever-increasing workload. In this report, we review the current literature on the prognostic impact of quantitation of tumor volume and/or size, taking into account the various objective and subjective methods of assessment currently employed.

Although the terms index tumor and dominant tumor are in common use in the literature, the validity of this concept is under scrutiny. ${ }^{5-7}$ As a consequence it was decided to seek clarification as to the understanding of these terms and, if necessary, make appropriate recommendations to clarify misconceptions. Finally, the significance of reporting on the zonal/anterior localization of the dominant or index tumor was discussed and opinions were sought as to whether or not this feature should be routinely documented in the pathology report.

\section{International Society of Urological Pathology Consensus Conference}

In order to identify the methods and practices most commonly employed by urological pathologists worldwide, a web-based survey on handling and reporting of radical prostatectomy specimens was distributed to 255 members of the International Society of Urological Pathology.

The International Society of Urological Pathology survey was followed up with a consensus conference held in conjunction with the 2009 Annual Scientific Meeting of the United States and Canadian Academy of Pathology held in Boston, Massachusetts. The aim was to obtain consensus relating to the handling, staging and reporting of radical prostatectomy specimens. Those who completed the electronic survey were invited to attend the consensus conference, which was held on 7 March. The detailed process related to the survey and consensus meeting are reported in an introductory paper. ${ }^{8}$

Representatives from five working groups appointed to coordinate the consensus process presented background information and results from detailed literature reviews to the meeting. The survey results were then discussed with the objective of achieving agreement on controversial issues. Following this, a ballot was taken on a series of questions, which was designed to address these controversial issues, and an achievement of $65 \%$ agreement on voting was considered to be consensus. With a few exceptions, there was agreement between the survey results and the consensus conference results. The results of the individual working group reports related to specimen handling, extraprostatic extension, seminal vesicle and lymph node involvement and margin status are reported separately. ${ }^{9-12}$

Many recommendations of this consensus conference have already been incorporated into international guidelines, including the recent College of American Pathologists protocol and checklist for reporting adenocarcinoma of the prostate and the structured reporting protocol for prostatic carcinoma from the Royal College of Pathologists of Australasia. ${ }^{13,14}$

\section{pT2 substaging}

\section{Clinicopathological Rationale for pT2 Substaging}

The objective of staging is to (1) group malignancies, which have an apparently similar prognosis, so as to inform a uniform therapeutic approach; (2) assist clinical trials and research studies by defining homogeneous patient populations; and (3) promote the international comparability of clinicopathological data from hospitals and research groups. 
Table 1 Comparison of TNM 1992/2002 and TNM 1997 criteria for staging of $\mathrm{T} 2$ prostate cancers

\begin{tabular}{llll}
\hline TNM 1992/TNM 2002/TNM 2010 & \multicolumn{2}{l}{ TNM 1997} \\
\hline T2a & Unilateral, less than half lobe & T2a & Unilateral \\
T2b & Unilateral, more than half lobe & T2b & Bilateral \\
T2c & Bilateral & - & - \\
\hline
\end{tabular}

In general, pathological substaging of tumors should maintain symmetry with clinical substaging, thus allowing direct comparison of cases. For prostate cancer this is difficult, especially for T2 tumors, as assigned clinical staging is a reflection of the detection methods employed. In particular the clinical substaging of T2 tumors is based on the extent of the abnormality detected during digital rectal examination (DRE) or demonstrated from transrectal ultrasonography (TRUS). In the 1997 revision of the TNM system, ${ }^{15}$ the clinical and pathological substaging of T2 cancers was simplified by the merging of palpable tumors occupying less than half of one lobe, with larger ones, into the single category of pT2a (Table 1). Following the adoption of this revised staging system, it was noted that clinical substaging, according to the 1992 classification, conveyed superior prognostic information to that of the 1997 classification. In particular, it was found that on digital examination cT2a tumors were able to be distinguished from cT2b and cT2c cancers. ${ }^{16,17}$ In view of this, the 2002 TNM clinical and pathological substaging of organ-confined (pT2) prostate cancers was redefined to distinguish unilateral cancer involving less (pT2a) or more (pT2b) than half of one lobe, from bilateral (pT2c) prostate cancers ${ }^{18}$ (Table 1). The pT2 substaging remained unchanged in the now adopted 2010 TNM system. ${ }^{2}$

In contrast to the clinical substaging of $\mathrm{T} 2$ cancers, the pathological substaging of tumors by either the 1997 or 2002/2010 TNM systems does not convey prognostic information. ${ }^{19,20}$ Further, the correlation of clinical and pathological substaging of T2 cancers is poor ${ }^{21,22}$ and, in particular, it has been shown that clinical substaging by DRE and TRUS results in understaging of pT2 tumors. ${ }^{4}$ As defined, clinical T2 substage of prostate cancers indirectly divides cases according to the likelihood of understaging and in this way clinical substaging seems to stratify a heterogeneous group of clinical stage T2 patients. ${ }^{23}$ This, however, does not hold true for the pathological substaging of pT2 cancers, as these cancers seem to represent a clinically (but not necessarily pathologically) homogeneous group with an overall good prognosis. ${ }^{19,24}$

From a biological perspective the current criteria for pT2 seem somewhat confusing. Multifocality of prostate cancer is commonplace, being found in $80 \%$ of prostatectomy specimens. ${ }^{7}$ The fact that in many cases this is only detectable histologically is
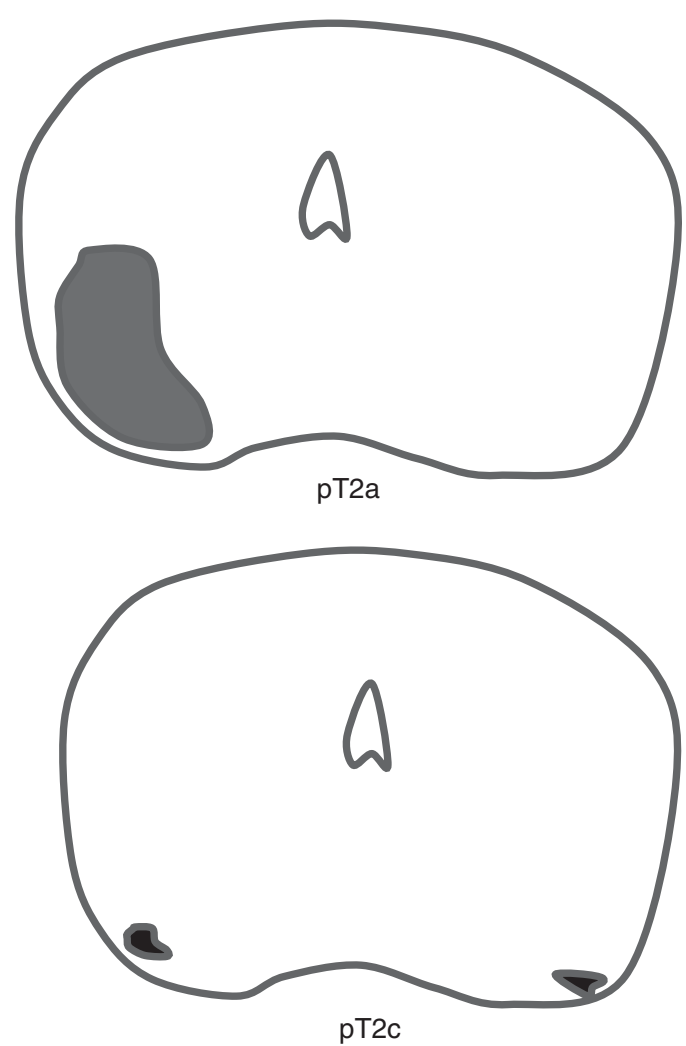

Figure 1 Multifocality as a confounder of pT2 substaging. A single large prostate cancer, involving less than half of a single side would represent stage pT2a (TNM 2002 and 2010), whereas two very small cancers distributed in the left and right half are considered stage pT2c prostate cancer.

a major confounder of the pT2 substaging system. A single unilateral large tumor would, for instance, be assigned a lower pathological stage than two small, bilateral cancers (Figure 1). Thus, it can be argued that substaging of pT2 cancers, using current criteria, lacks any rationale.

\section{Technical Aspects of pT2 Substaging}

In reports to date, there is a large variation in the distribution of TNM 2002 pT2 substages among different prostate cancer series, with pT2b varying from 0 to $19.1 \%$ of cases. ${ }^{24-26}$ This observation points at a lack of uniform criteria used to define pT2 substaging, giving rise to poor reproducibility. In particular, the criteria to distinguish prostate cancers involving less than a half lobe from those involving more than a half lobe are not well defined and are not applied consistently. It appears that some pathologists employ a visual estimate method, ${ }^{25}$ whereas others use a point counting method $^{26}$ or count the number of slides that are cancer positive and cancer negative, ${ }^{16}$ in order to differentiate pT2a from pT2b tumors.

Surprisingly, the majority $(74 \%)$ of pathologists who responded to the pre-meeting survey considered 
Table 2 Results of survey and voting-questions relating to pT2 subcategorization

\begin{tabular}{|c|c|c|c|}
\hline Survey results & $\%$ of responses & $\begin{array}{l}\text { No. of } \\
\text { responses }\end{array}$ & Current practice \\
\hline Relevance of pT2 substaging? & $\begin{array}{l}\text { Yes, (academic): } 40 \% \text {; yes, } \\
\text { (clinical): } 34 \% \text {; not relevant: } 25 \%\end{array}$ & 154 & \multirow[t]{2}{*}{$\begin{array}{l}\text { Reporting of pT2 } \\
\text { substage }\end{array}$} \\
\hline Reporting pT2 substaging? & $\begin{array}{l}\text { Yes: } 85 \% \\
\text { No: } 15 \%\end{array}$ & 156 & \\
\hline Frequency of pT2b reporting (\% of cases) & $<5 \%: 44 ; 5-20 \%: 30 ;$ and $>20 \%: 8 \%$ & 127 & Large variation \\
\hline Method of distinguishing pT2b and pT2a & $\begin{array}{l}\text { Slide counting: } 22 \% \\
\text { Eyeballing: } 47 \% \text {; other: } 12 \%\end{array}$ & 123 & Variable \\
\hline $\begin{array}{l}\text { Substage of one dominant tumor and (few) } \\
\text { additional smaller contralateral tumors }\end{array}$ & $\begin{array}{l}\text { pT2c: } 78 \% \text { ( } 48 \% \text { of them added a } \\
\text { comment that the side of dominant } \\
\text { tumor should be reported) }\end{array}$ & 129 & \multirow{2}{*}{$\begin{array}{l}\text { Assignment of } \\
\text { pT2c substage } \\
\text { irrespective } \\
\text { of the size of } \\
\text { contralateral } \\
\text { tumor(s) }\end{array}$} \\
\hline $\begin{array}{l}\text { Substage of one dominant tumor and one very } \\
\text { small contralateral tumor }(<2 \mathrm{~mm})\end{array}$ & $\begin{array}{l}\text { pT2a: } 3 \% \\
\text { pT2c: } 71 \% \text { ( } 51 \% \text { of them added a } \\
\text { comment that the side of the } \\
\text { dominant tumor should be reported) }\end{array}$ & 131 & \\
\hline Voting results of ISUP consensus conference & $\%$ of responses & $\begin{array}{l}\text { No. of } \\
\text { responses }\end{array}$ & Consensus \\
\hline Continuation of pT2 substaging? & $\begin{array}{l}\text { Yes: } 35 \% \\
\text { No: } 65 \%\end{array}$ & 110 & Yes \\
\hline Return to two-tier pT2 substaging (pT2a/b)? & $\begin{array}{l}\text { Yes: } 63 \% \\
\text { No: } 37 \%\end{array}$ & 101 & No \\
\hline $\begin{array}{l}\text { If three-tier pT2 substaging is to be } \\
\text { maintained, a cutoff measure should be } \\
\text { defined? }\end{array}$ & $\begin{array}{l}\text { Yes: } 74 \% \\
\text { No: } 26 \%\end{array}$ & 98 & Yes \\
\hline $\begin{array}{l}\text { Minimum size requirement of contralateral } \\
\text { tumor for pT2c? }\end{array}$ & $\begin{array}{l}\text { Yes: } 40 \% \\
\text { No: } 60 \%\end{array}$ & 104 & No \\
\hline
\end{tabular}

pT2 substaging clinically and/or academically relevant (Table 2) and we would suggest that this provides some explanation for the observation that reporting of pT2 substaging is widely employed in current practice. The survey results further confirmed the findings prevalent in the literature that the frequency of reporting of pT2b prostate cancer varies widely among pathologists, ranging from $<5 \%$ to $>20 \%$ of reported cases. Of interest, the largest group of respondents, representing slightly less than half of the total number of participants, indicated that they reported tumors as pT2b prostate cancers in $<5 \%$ of cases. The survey further demonstrated that the techniques used to distinguish pT2a from pT2b were variable, although the majority of respondents reported that they used a slide counting method (Table 2).

The survey clearly demonstrated that most pathologists assign a pT2c stage to bilateral prostate cancers, regardless of the size of the cancer contralateral to the dominant or largest tumor. Of the surveyed pathologists, $48 \%$ noted that they would add a comment to the report, in the case of a pT2c prostate cancer in which there was a large dominant nodule, with one or more very small and probably clinically insignificant contralateral foci of tumor.
At the consensus conference the validity of the current pT2 substaging system was discussed after the presentation of background data. The majority $(65.5 \%)$ of participants felt that the current pT2 substaging of prostate cancers should be discontinued. If the pT2 category was to be maintained, the majority of participants preferred to see a return to a two-tier subcategorization for pT2 (unilateral versus bilateral prostate cancer) as defined in the 1992 TNM classification. A consensus was achieved for the view that a minimum size or volume measure should be employed as a cutpoint to distinguish unilateral (pT2a) from bilateral (pT2c) cancers, although no agreement was reached as to the defining value of such a cutpoint (Figure 2). It was proposed that for a tumor to be classified as pT2c, the contralateral tumor should be at least $1 \mathrm{~cm}$ in diameter (approximately equal to $0.5 \mathrm{ml}$ ). It was argued that this would be consistent with the criteria employed for clinical T2 substaging; however, no consensus was reached on this proposal.

The consensus conference concluded that consensus was reached to discontinue the use of the current pT2 substaging system. In view of the lack of clinical significance of the current (TNM 2002/2010) pT2 subcategories, there was general agreement in the subsequent discussion for the recommendation 


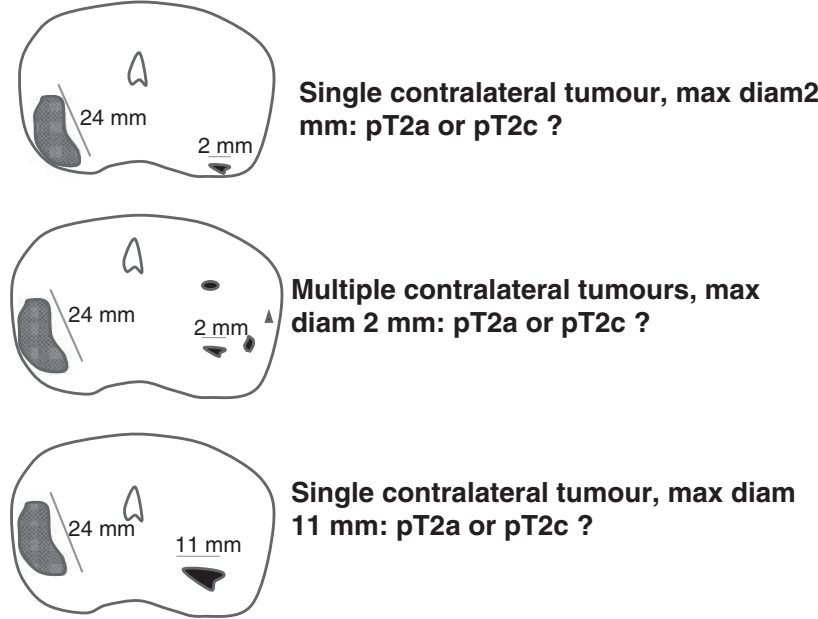

Figure 2 The effect of a maximum diameter threshold of the contralateral tumor on pT2 substage. If a $10-\mathrm{mm}$ maximum diameter threshold of the largest contralateral tumor is used, only the lower prostatectomy specimen would be assigned as pT2c prostate cancer.

that the reporting of pT2 substaging of prostate cancers should be optional.

\section{Prostate cancer volume and/or size assessment}

\section{Clinicopathological Rationale for the Assessment of Volume and/or Size of Prostate Cancer}

Tumor volume of prostate cancers in radical prostatectomy specimens has been correlated with histological grade, stage, tumor progression and patient survival. Tumor volume has also been shown to predict the development of metastasis, seminal vesicle invasion and extraprostatic extension of tumor. ${ }^{27-31}$ Some studies have shown the percentage of prostatic tissue involved by tumor to exhibit a stronger association with pathological stage and tumor progression than tumor volume ${ }^{29,30} \mathrm{~A}$ recent study has further demonstrated that cancer volume was an independent predictor of overall survival in patients with prostate cancer, although no data on prostate cancer specific mortality were provided. ${ }^{32}$ Some reports provide evidence that measurement of the volume of the dominant or index tumor alone is an equally powerful predictor of prognosis as volume assessment of all tumor nodules in a prostatectomy specimen. ${ }^{33}$ Although the prognostic significance of quantitation of prostate cancer volume and the proportion of prostate gland tissue involved by carcinoma is not disputed, few studies are able to provide evidence that parameters reflecting prostate cancer volume are of significance, independent of Gleason score, pathological stage and surgical margin status. ${ }^{34-37}$ The study by Stamey et $a l^{34}$ was undertaken on a series of prostatectomy specimens that antedated the PSA screening era, and for this reason tumors in this series were much more advanced than those currently identified in the current era of patient and physician directed screening. More recently Eichelberger et $a l^{37}$ did demonstrate that measurement of the maximum diameter of the dominant tumor has independent prognostic value. However, it should be noted that in this series the patients had very short follow-up, with a median follow-up interval of only 12 months. As a consequence, in this report, surgical margin status failed to reach significance as a predictor of biochemical failure. The earlier study by Renshaw et $a l^{35}$ that demonstrated the independent significance of maximum tumor diameter of the largest tumor focus was followed by a more recent study from the same institution on a larger cohort of patients. In this series, which incorporates surgical margin status in the multivariate analysis, tumor volume failed to achieve significance as an independent prognostic factor. ${ }^{38}$ Several other studies have similarly been unable to demonstrate the independent significance of tumor volume as a prognostic factor for prostate cancer. ${ }^{39-46}$ In conclusion, all studies reported to date demonstrate that parameters of prostate cancer volume correlate with other prognostic features, but that the independent prognostic value of this parameter remains uncertain.

To justify reporting of a prognostic parameter in routine clinical practice, it is necessary to demonstrate its predictive value independent of other established prognostic parameters. Further, the prognostic significance of the parameter needs to be to the extent that the clinical value of the information derived from it justifies the additional burden and expense associated with data collection. Imaging technology is now making such progress that visualization of most prostate cancers of a volume in the order of $0.5 \mathrm{ml}$ is possible. It is envisaged that, in the future, further advances in imaging techniques will result in more accurate clinical estimations of the volume or the maximum diameter of the index tumor. It is anticipated that this will serve to reinforce the clinical rationale for incorporating a size-related staging parameter into pathological reporting of prostate cancers.

\section{Measurement of Tumor Volume}

A unified methodology for the measurement and subsequent reporting of cancer volume in radical prostatectomy specimens has long been seen as a controversial area of urological pathology. ${ }^{43}$ No accepted standard for the measurement of tumor volume exists as its assessment is technically much more difficult than for most other organs. ${ }^{47}$ Some institutions calculate tumor volume using computer-assisted image analysis systems; ${ }^{47,48}$ however, as this method is not appropriate for routine clinical practice, alternative methods have been proposed. These methods include streamlined three-dimensional volume estimation, ${ }^{49}$ measurement of the diameter of the largest tumor focus, ${ }^{37,38}$ assessment 
Table 3 Results of survey and voting-questions relating to tumor size, definition of the dominant/index tumor and zonal location

\begin{tabular}{|c|c|c|c|}
\hline Survey results & $\%$ of responses & No. of responses & Current practice \\
\hline Reporting of tumor size/volume? & $\begin{array}{l}\text { Yes: } 88 \% \\
\text { No: } 12 \%\end{array}$ & 156 & $\begin{array}{l}\text { Size/volume of } \\
\text { carcinoma is reported }\end{array}$ \\
\hline Methodology for tumor size assessment & $\begin{array}{l}\text { Diameter largest tumor: } 35 \% \text {, } \\
\text { visual inspection } 23 \% \text {, several } \\
\text { other methods specified }\end{array}$ & $\begin{array}{l}154 \text { ( } 42 \text { of them do } \\
\text { not report on size) }\end{array}$ & Variable \\
\hline Methodology for tumor volume assessment & $\begin{array}{l}\text { Visual inspection, using } \\
\text { quantitative term: } 37 \% \text {, several } \\
\text { other methods specified }\end{array}$ & $\begin{array}{l}156 \text { ( } 40 \text { of them do not } \\
\text { report on volume) }\end{array}$ & Variable \\
\hline Routinely reporting of zonal origin of tumor? & $\begin{array}{l}\text { Yes: } 47 \% \\
\text { No: } 53 \%\end{array}$ & 157 & Variable \\
\hline Voting results of ISUP consensus conference & $\%$ of responses & No. of responses & Consensus \\
\hline Reporting a measure of tumor size? & $\begin{array}{l}\text { Yes: } 97 \% \\
\text { No: } 3 \%\end{array}$ & 110 & $\begin{array}{l}\text { Yes: hand vote also } \\
\text { showed consensus for } \\
\text { reporting a figure }\end{array}$ \\
\hline Reporting maximum diameter of index tumor? & $\begin{array}{l}\text { Yes: } 52 \% \\
\text { No: } 48 \%\end{array}$ & 107 & No \\
\hline Reporting of zonal/anterior location of index tumor? & $\begin{array}{l}\text { Yes: } 69 \% \\
\text { No: } 31 \%\end{array}$ & 110 & Yes \\
\hline
\end{tabular}

of maximum tumor area using a single or multiple slide approach, ${ }^{50}$ counting of the number of involved blocks, ${ }^{51}$ assessment of the positive to negative block ratio, ${ }^{52}$ use of an integration measuring grid, ${ }^{27}$ point counting, ${ }^{53,54}$ naked eye examination of the glass slides after all microscopically identifiable foci of carcinoma have been circled with a marking pen, ${ }^{55}$ or, most simply, naked eye examination of sections without marking of tumor foci. ${ }^{36}$ Authors of several landmark studies ${ }^{34,35,37,50}$ have put forward that measurement of size or volume may be limited to assessment of the largest tumor nodule in a prostatectomy specimen and a method that may be appropriate is measurement of the maximum diameter of the largest tumor nodule in the transverse plane, after delineating the edges of the tumor on the glass slide. ${ }^{56}$ Potential complications for absolute measurement of tumor diameter in volume may arise when (1) the tumor extends beyond the glass slide; (2) the prostate is not fully embedded; (3) tissue blocks are cut at irregular intervals; and (4) shrinkage of tissue occurs due to processing, which may vary between laboratories.

Both the pre-meeting survey and voting during the consensus meeting revealed widespread support for the incorporation of some form of tumor volume assessment into the pathology report of radical prostatectomy specimens (Table 3). There was a strong consensus at the meeting for the reporting of tumor size or volume, and delegates favored the recording of a numerical value rather than a subjective descriptor such as small or large volume tumor. It was noted that several synoptic protocols for the reporting of prostatectomy specimens now include the option of providing an assessment of tumor volume and there was considerable discussion regarding the effort pathologists should invest in deriving this parameter.

It was felt that in those laboratories where the preparation of whole-mount sections of prostate is routine, the performance of morphometric measurements of the dominant tumor would be relatively straightforward. Conversely, in laboratories that employ protocols that utilize incomplete embedding of prostatectomies, visual estimation of the proportion of cancer only may be feasible. The survey showed that $<10 \%$ of respondents derive information on volume or size of prostate cancer through the use of a grid or by computer-assisted morphometry. Visual estimation was reported as the most common method used for volume assessment, and this was the second most frequently used technique after measurement of maximum diameter for the determination of tumor size (Table 3 ).

At the consensus conference, voting was almost equally split on the proposal to adopt the measurement of maximum diameter of the dominant tumor nodule as a standard for reporting tumor size (Table 3). It was, however, stated that in view of the potential importance of tumor size as a prognostic parameter, coupled with the recent advances in imaging technology, it may prove necessary to embrace more sophisticated methods for measuring tumor diameter. This was considered of some importance as some argued that tumor size may become more important as a defining parameter for both clinical and pathological staging. 
Table 4 Voting results on definition of index tumor

\begin{tabular}{lc}
\hline Definition index tumor & \% of total 100 votes \\
\hline Largest tumor & 24 \\
Highest Gleason score & 8 \\
Highest stage & 9 \\
Size and grade & 29 \\
Stage and grade & 28 \\
Size and stage & 2 \\
\hline
\end{tabular}

For patients with clinically insignificant cancers, defined as organ-confined (pT2), no more than $10 \mathrm{~mm}$ in diameter and no more than Gleason score $6,{ }^{57}$ the option was discussed to include a separate comment in the report in order to point out that these tumors are rarely, if at all, associated with biochemical failure, provided that the surgical margins of the prostatectomy specimen are negative..$^{58}$

Consensus was obtained that, as a minimum requirement for the reporting of prostate cancer in radical prostatectomy specimens, some quantitative estimate of cancer volume should be undertaken, the nature of which being dependent on routine practice within the pathology laboratory (Table 3). It was recommended that each laboratory should adopt a well-defined and standardized protocol and that this be used by all pathologists within the institution who report radical prostatectomy specimens. Further, based on the discussion, it was recommended that for tumors, which are considered to be clinically insignificant by established criteria ${ }^{57}$ specific mention should be made of this in the report.

\section{Definition of index tumor}

The concept of an index or dominant tumor was derived from the Stanford group who, after delineating the contours of prostate cancers on whole-mount sections, measured the volume of the largest tumor nodule and correlated this with outcome. ${ }^{31}$

This concept is, however, now being challenged on two grounds. First, several subsequent studies have failed to demonstrate the independent prognostic significance of the dominant tumor nodule and, second, because the dominant nodule does not always represent the component of tumor having the highest Gleason score or the most advanced pathological stage. ${ }^{7}$

There was no consensus as to the defining features of the dominant/index tumor in a radical prostatectomy specimen. Analysis of the voting results (Table 4) showed the greatest support for the concept that tumor size and Gleason grade are the two most important parameters to be considered when defining the dominant or index tumor. This would mean that if two tumor nodules each had a similar Gleason score, then the larger tumor should be considered to be the dominant or index tumor. In the case of two tumors nodules having differing
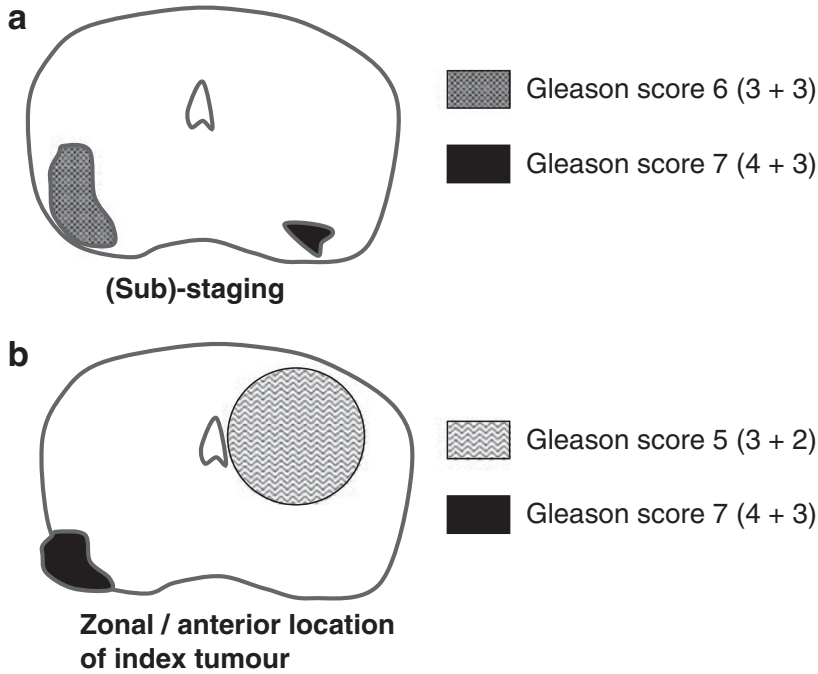

Figure 3 The definition of the index tumor may depend on the context; for substaging the index tumor could be defined as largest tumor (a). (b) The biologically most significant cancer is most likely the pT3 Gleason score $7(4+3)$ carcinoma. As a consequence, in this example the index tumor is located in the peripheral zone.

Gleason scores, the nodule with the higher score should be considered to be the dominant or index tumor, regardless of size. Slightly less support was obtained for the suggestion that the dominant or index tumor should be defined on the basis of pT category.

It was agreed that the terms dominant or index tumor are context dependent (Figure 3). When used to identify the component of a tumor whose volume/ size is considered as a prognostic parameter or a defining feature of pT2 substaging, the Stanford group definition of the tumor nodule having the largest size was considered to be most appropriate. Conversely, other features may influence the clinical importance of the largest tumor nodule and other nodules, and in particular, pT category and Gleason grade/score, may need to be included in the defining characteristics. It was suggested that the tumor with the highest grade and/or stage might also be more appropriately considered to be the dominant/index tumor for the purpose of correlating imaging studies with subsequent prostatectomy findings.

\section{Zonal origin of prostate cancer}

\section{Clinicopathological Rationale for Reporting Zonal Origin of Prostate Cancer}

Most studies have demonstrated that transition zone cancers have more favorable pathological features with lower Gleason score and pathological stage. These tumors also have a greater likelihood of a longer biochemical failure-free interval for patients whose tumors recur after attempted curative therapy than cancers originating from the peripheral zone. ${ }^{59-62}$ This longer biochemical 
failure-free interval appears to be independent of tumor volume. ${ }^{59,61}$

In a further series it was shown that, in spite of significantly higher PSA levels as well as greater tumor volume, when compared with those of peripheral zone cancers, tumors from the transition zone showed similar biochemical cure rates following radical prostatectomy. This again suggests a less aggressive phenotype for transition zone cancers when compared with tumors from the peripheral zone. ${ }^{63}$ Contradictory findings have also been reported. In two studies comparing the distribution of Gleason scores in peripheral zone and transition zone cancers, no significant difference was noted in the proportions of Gleason score 6 and 7 carcinomas. $^{64,65}$ Further, tumor-positive anterior and bladder neck margins were found to be more frequent in transition zone carcinomas than those from the peripheral zone. ${ }^{61}$ Augustin et $a l^{66}$ analyzed the zonal location of prostate cancers as a possible predictive feature of progression-free survival after radical prostatectomy. They reported that prostate cancers located in the transition zone were associated with a greater biochemical cure rate after radical prostatectomy, but that zonal location was not an independent prognostic factor on multivariate analysis.

From a clinical perspective, it is also important to determine whether there is involvement of the anterior part of the prostate, as cancers of peripheral or transition zone origin may also be predominantly located in the anterior prostate gland. ${ }^{65}$ These tumors are less likely to be detected by standard biopsy procedures and may be associated with a higher incidence of margin positivity and increased risk of biochemical failure. ${ }^{67}$

\section{Technical Aspects}

The zonal origin of prostate carcinoma is more difficult to determine on standard sectioning of prostatectomy specimens when compared with whole-mount sections. Often prostate cancers involve both the peripheral and transition zone and under such circumstances the Gleason pattern (Gleason grade 2 versus 3 ) may assist in determining whether or not the tumor is of transition or peripheral zone origin. The presence of the largest proportion of a carcinoma in the transition zone might also be considered to be useful evidence that a tumor has arisen within the transition zone.

In the pre-meeting survey, respondents were equally divided on the question as to whether they routinely report the zonal origin of prostate cancers. During the conference, consensus was achieved for the recommendation that the zonal localization of the dominant/index tumor in prostatectomy specimens should be included in the pathology report. There was also consensus that the report should note when the dominant tumor involves the anterior portion of the gland (Table 3 ).
It is recommended that, where possible, the location of the dominant or index tumor, however defined, be specified. It was also agreed that if the tumor is sited anteriorly, this should be documented.

\section{Disclosure/conflict of interest}

The authors declare no conflict of interest.

\section{References}

1 Gallina A, Chun FK, Suardi N, et al. Comparison of stage migration patterns between Europe and the USA: an analysis of 11350 men treated with radical prostatectomy for prostate cancer. BJU Int 2008;101:1513-1518.

2 International Union Against Cancer (UICC). In: Sobin LH, Gospodariwicz M, Wittekind C (eds). TNM Classification of Malignant Tumors 7th edn. WileyBlackwell: Oxford, UK, 2009, pp 243-248.

3 Van der Kwast TH. Substaging pathologically organ confined (pT2) prostate cancer: an exercise in futility? Eur Urol 2006;49:209-211.

4 Van Oort IM, Witjes JA, Kok DE, et al. The prognostic role of the pathological T2 subclassification for prostate cancer in the 2002 Tumour-Nodes-Metastasis staging system. BJU Int 2008;102:438-441.

5 Qian J, Hirasawa K, Bostwick DG, et al. Loss of p53 and c-myc overrepresentation in stage T2-3NI-3M0 prostate cancer are potential markers for cancer progression. Mod Pathol 2002;15:35-44.

6 Schmidt H, DeAngelis G, Eltze E, et al. Asynchronous growth of prostate cancer is reflected by circulating tumor cells delivered from distinct, even small foci, harboring loss of heterozygosity of the PTEN gene. Cancer Res 2006;66:8959-8965.

7 Andreoiu M, Cheng L. Multifocal prostate cancer: biologic, prognostic, and therapeutic implications. Human Pathol 2010;41:781-793.

8 Egevad L, Srigley JR, Delahunt B. International Society of Urological Pathology (ISUP) consensus conference on handling and staging of radical prostatectomy specimens: rationale and organization. Mod Pathol 2011;24:1-5 (this issue).

9 Samaratunga $\mathrm{H}$, Montironi $\mathrm{R}$, True L, et al. International Society of Urological Pathology (ISUP) consensus conference on handling and staging of radical prostatectomy specimens. Working group 1: specimen handling. Mod Pathol 2011;24:6-15 (this issue).

10 Magi-Galluzzi C, Evans A, Epstein JI, et al. International Society of Urological Pathology (ISUP) consensus conference on handling and staging of radical prostatectomy specimens. Working group 3: extraprostatic extension, lymphovascular invasion and locally advanced disease. Mod Pathol 2011;24:26-38 (this issue).

11 Berney D, Wheeler T, Grignon D, et al. International Society of Urological Pathology (ISUP) consensus conference on handling and staging of radical prostatectomy specimens. working group 4: seminal vesicles and lymph nodes. Mod Pathol 2011;24:39-47 (this issue).

12 Tan PH, Cheng L, Srigley JR, et al. International Society of Urological Pathology (ISUP) consensus conference on handling and staging of radical prosta- 
tectomy specimens. Working group 5: surgical margins. Mod Pathol 2011;24:48-57 (this issue).

13 Srigley JR, Humphrey PA, Amin MB, et al. Protocol for the examination of specimens from patients with carcinoma of the prostate gland. Arch Pathol Lab Med 2009;133:1568-1576.

14 Kench J, Clouston D, Delahunt B, et al. Royal College of Pathologists of Australasia Prostate Cancer (Radical Prostatectomy) Structured Reporting Protocol. 2010, pp 54. http://www.rcpa.edu.au/Publications/StructuredReporting/CancerProtocols.htm.

15 International Union Against Cancer (UICC). In: Sobin LH, Wittekind Ch (eds). TNM Classification of Malignant Tumours, 5th edn. Wiley-Liss: New York, 1997, pp 170-173.

16 Armatys SA, Koch MO, Bihrle R, et al. Is it necessary to separate clinical stage T1c from T2 prostate adenocarcinoma? BJU Int 2005;96:777-780.

17 Freedland SJ, Presti Jr JC, Terris MK, et al. The SEARCH Database Study Group. Improved clinical staging system combining biopsy laterality and TNM stage for men with T1c and T2 prostate cancer: results from the SEARCH database. J Urol 2003;169:2129-2135.

18 International Union Against Cancer (UICC). In: Sobin LH, Wittekind Ch (eds). TNM Classification of Malignant Tumours, 6th edn. Wiley-Liss: New York, 2002, pp 184-187.

19 Freedland SJ, Partin AW, Epstein JI, et al. Biochemical failure after radical prostatectomy in men with pathologic organ-confined disease: pT2a versus pT2b. Cancer 2004;100:1646-1649.

20 Hong SK, Han BK, Chung JS, et al. Evaluation of pT2 subdivisions in the TNM staging system for prostate cancer. BJU Int 2008;102:1092-1096.

21 Bostwick DG. Staging prostate cancer-1987: current methods and limitations. Eur Urol 1997;32(S3):2-14.

22 Hoedemaeker RF, Rietbergen JB, Kranse R, et al. Comparison of pathologic characteristics of T1c and non-T1c cancers detected in a population-based screening study, the European Randomized Study of Screening for Prostate Cancer. World J Urol 1997; 15:339-345.

23 Ramos CG, Carvalhal GF, Smith DS, et al. Clinical and pathological characteristics, and recurrence rates of stage T1c versus T2a or T2b prostate cancer. J Urol 1999;16:1525-1529.

24 May F, Hartung R, Breul J. The ability of the American Joint Committee on Cancer Staging system to predict progression-free survival after radical prostatectomy. BJU Int 2001;88:702-707.

25 Eichelberger LE, Cheng L. Does pT2b cancer exist? Critical appraisal of the 2002 TNM classification of prostate cancer. Cancer 2004;100:2573-2576.

26 Quintal MM, Magna LA, Guimaraes MS, et al. Prostate cancer pathologic stage pT2b (2002 TNM staging system): does it exist? Int Braz J Urol 2006;32:43-47.

27 Humphrey PA, Vollmer RT. Intraglandular tumor extent and prognosis in prostatic carcinoma: application of a grid method to prostatectomy specimens. Hum Pathol 1990;21:799-804.

28 McNeal JE, Bostwick DG, Kindrachuk RA, et al. Patterns of progression in prostate cancer. Lancet 1986;1:60-63.

29 Epstein JI, Oesterling JE, Walsh PC. Tumor volume versus percentage of specimen involved by tumor correlated with progression in stage A prostatic carcinoma. J Urol 1988;139:980-984.
30 Partin AW, Epstein JI, Cho KR, et al. Morphometric measurement of tumor volume and per cent of gland involvement as predictors of pathological stage in clinical stage B prostate cancer. J Urol 1989;141:341-345.

31 McNeal JE, Price HM, Redwine EA, et al. Stage A versus stage $\mathrm{B}$ adenocarcinoma of the prostate: morphological comparison and biological significance. J Urol 1988;139:61-65.

32 Vollmer RT. Percentage of tumor in prostatectomy specimens: a study of American Veterans. Am J Clin Pathol 2009;131:86-91.

33 Wise AM, Stamey TA, McNeal JE, et al. Morphologic and clinical significance of multifocal prostate cancers in radical prostatectomy specimens. Urology 2002;60: 264-269.

34 Stamey TA, McNeal JE, Yemoto CM, et al. Biological determinants of cancer progression in men with prostate cancer. JAMA 1999;281:1395-1400.

35 Renshaw AA, Richie JR, Loughlin KR, et al. Maximum diameter of prostatic carcinoma is a simple, inexpensive, and independent predictor of prostate-specific antigen failure in radical prostatectomy specimens. Am J Clin Pathol 1999;111:641-644.

36 Carvalhal GF, Humphrey PA, Thorson P, et al. Visual estimate of the percentage of carcinoma is an independent predictor of prostate carcinoma recurrence after radical prostatectomy. Cancer 2000;89:1308-1314.

37 Eichelberger LE, Koch MO, Eble JN, et al. Maximum tumor diameter is an independent predictor of prostate specific antigen recurrence in prostate cancer. Mod Pathol 2005;18:886-890.

38 Dvorak T, Chen MH, Renshaw AA, et al. Maximal tumor diameter and the risk of PSA failure in men with specimen-confined prostate cancer. Urology 2005;66: 1024-1028.

39 Epstein JI, Carmichael M, Partin AW, et al. Is tumor volume an independent predictor of progression following radical prostatectomy? A multivariate analysis of 185 clinical stage B adenocarcinoma of the prostate with 5 years of follow-up. J Urol 1993;149:1478-1485.

40 Salomon L, Levrel O, Anastasiadis AG, et al. Prognostic significance of tumor volume after radical prostatectomy: a multivariate analysis of pathological prognostic factors. Eur Urol 2003;43:39-44.

41 Lerner SE, Blute ML, Zincke H. Risk factors for progression in patients with prostate cancer treated with radical prostatectomy. Semin Urol Oncol 1996;14(Suppl 2):12-20.

42 Ohori M, Wheeler TM, Kattan MW, et al. Prognostic significance of positive surgical margins in radical prostatectomy specimens. J Urol 1995;154:1818-1824.

43 Epstein JI. Pathologic assessment of the surgical specimen. Urol Clin Nth Am 2001;28:567-594.

44 Van Oort IM, Witjes JA, Kok DE, et al. Maximum tumor diameter is not an independent prognostic factor in high-risk localized prostate cancer. World J Urol 2008;26:237-241.

45 Kikuchi E, Scardino PT, Wheeler TM, et al. Is tumor volume an independent prognostic factor in clinically localized prostate cancer? J Urol 2004;172:508-511.

46 Wolters T, Roobol MJ, van Leeuwen PJ, et al. Should pathologists routinely report prostate tumour volume? The prognostic value of tumour volume in prostate cancer. Eur Urol (in press).

47 Bostwick DG, Montironi R. Evaluating radical prostatectomy specimens: therapeutic and prognostic importance. Virchow Arch 1997;430:1-16. 
48 Noguchi M, Stamey TA, McNeal JE, et al. Assessment of morphometric measurements of prostate carcinoma volume. Cancer 2000;89:1056-1064.

49 Chen ME, Johnston D, Reyes AO, et al. A streamlined three-dimensional volume estimation method accurately classifies prostate tumors by volume. Am J Surg Pathol 2003;27:1291-1301.

50 Renshaw AA, Chang H, D'Amico AV. Estimation of tumor volume in radical prostatectomy specimens in routine clinical practice. Am J Clin Pathol 1997; 107:704-708.

51 Jones EC. Resection margin status in radical retropubic prostatectomy specimens: relationship to type of operation, tumor size, tumor grade and local tumor extension. J Urol 1990;144:89-93.

52 Marks RA, Lin H, Koch MO, et al. Positive-block ratio in radical prostatectomy specimens is an independent predictor of prostate-specific antigen recurrence. Am J Surg Pathol 2007;31:877-881.

53 Billis A, Magna LA, Ferreira U. Correlation between tumor extent in radical prostatectomies and preoperative PSA, histological grade, surgical margins, and extraprostatic extension: application of a new practical method for tumor extent evaluation. Int Braz J Urol 2003;29:113-120.

54 Billis A, Freitas LLL, Magna LA, et al. Prostate cancer with bladder neck involvement: pathologic findings with application of a new practical method for tumor extent evaluation and recurrence-free survival after radical prostatectomy. Int Urol Nephrol 2004;36: 363-368.

55 Cantrell BB, DeKlerk DP, Eggleston JC, et al. Pathologic factors that influence prognosis in stage A prostatic cancer: the influence of extent versus grade. J Urol 1981;125:516-520.

56 Mai KT, Mokhtar G, Burns BF, et al. A simple technique for calculations of the volume of prostatic adenocarcinomas in radical prostatectomy specimens. Pathol Res Pract 2003;199:599-604.

57 Epstein JI, Walsh PC, Carmichael M, et al. Pathologic and clinical findings to predict tumor extent of

\section{Appendix 1}

The members of the ISUP Prostate Cancer Group are the following:

Adebowale Adeniran, Hikmat Al-Ahmadie, Ferran Algaba, Robert Allan, Mahul Amin, Marc Barry, Sheldon Bastacky, Dilek Baydar, Louis Bégin, Dan Berney, Athanase Billis, Liliane Boccon-Gibod, David Bostwick, Maria Brito, Tucker Burks, Christer Busch, Philippe Camparo, Liang Cheng, Cynthia Cohen, Milton Datta, Laurence de Leval, Brett Delahunt, Warick Delprado, Lars Egevad, Jonathan Epstein, Andrew Evans, Sara Falzarano, Samson Fine, Eddie Fridman, Bungo Furusato, Masoud Ganji, Lisa Glantz, Anuradha Gopalan, David Grignon, Rainer Grobholz, Charles Guo, Rekha Gupta, Bora Gurel, Seife Hailemariam, Ardeshir Hakam, Omar Hameed, Donna Hansel, R.-Peter Henke, Mehsati Herawi, Michelle Hirsch, Jiaoti Huang, Wei Huang, Christina Hulsbergen van de Kaa, Peter Humphrey, Kenneth Iczkowski, Edward Jones, Michael Jones, Laura Jufe, James Kench, nonpalpable (stage T1c) prostate cancer. JAMA 1994; 271:368-374.

58 Postma R, de Vries SH, Roobol MJ, et al. Incidence and follow-up of patients with focal prostate carcinoma in 2 screening rounds after an interval of 4 years. Cancer 2005;103:708-716.

59 Noguchi M, Stamey TA, McNeal JE, et al. An analysis of 148 transition zone cancers: clinical and histological characteristics. J Urol 2000;163:1751-1755.

60 Erbersdobler A, Huhle S, Palisaar J, et al. Pathological and clinical characteristics of large prostate cancers predominantly located in the transition zone. Prostate Cancer Prostatic Dis 2002;5:279-284.

61 Shannon BA, McNeal JE, Cohen RJ. Transition zone carcinoma of the prostate gland: a common indolent tumour type that occasionally manifests aggressive behavior. Pathology 2003;35:467-471.

62 Greene DR, Fitzpatrick JM, Scardino PT. Anatomy of the prostate and distribution of early prostate cancer. Semin Surg Oncol 1995;11:9-22.

63 Sakai I, Harada K, Kurahashi T, et al. Analysis of differences in clinicopathological features between prostate cancers located in the transition and peripheral zones. Int J Urol 2006;13:368-372.

64 Sakai I, Harada K, Hara I, et al. A comparison of the biological features between prostate cancers arising in the transition and peripheral zones. BJU Int 2005; 96:528-532.

65 Al-Ahmadie HA, Tickoo SK, Olgac S, et al. Anteriorpredominant prostatic tumors: zone of origin and pathologic outcomes at radical prostatectomy. Am J Surg Pathol 2008;32:229-235.

66 Augustin H, Hammerer PG, Blonski J, et al. Zonal location of prostate cancer: significance for diseasefree survival after radical prostatectomy? Urology 2003;62:79-85.

67 Miyake H, Sakai I, Ishimura T, et al. Significance of cancer detection in the anterior lateral horn on systematic prostate biopsy: the effect on pathological findings of radical prostatectomy specimens. BJU Int 2004;93:57-59.

Hyun-Jung Kim, Peter Kragel, Glen Kristiansen, Katia Ramos Moreira Leite, Claudio Daniel Lewin, Josep Lloreta, Antonio Lopez-Beltran, Scott Lucia, Dani el Luthringer, Cristina Magi-Galluzzi, Peter McCue, Teresa McHale, Jesse McKenney, Maria Merino, Rodolfo Montironi, Gabriella Nesi, George Netto, Esther Oliva, Pedro Oliveira, Adeboye Osunkoya, Gladell Paner, Anil Parwani, Maria Picken, Galina Pizov, Andrew Renshaw, Jae Ro, Stephen Rohan, Ruben Ronchetti, Mark Rubin, Hemamali Samaratunga, Anna Sankila, Alan Schned, Isabell Sesterhenn, Ahmed Shabaik, Rajal Shah, Jonathan Shanks, Steven Shen, Jungweon Shim, Taizo Shiraishi, VO Speights Jr, John Srigley, Ming-Tse Sung, Sueli Suzigan, Hiroyuki Takahashi, Puay Hoon Tan, Bernard Têtu, Satish Tickoo, John Tomaszewski, Patricia Troncoso, Kiril Trpkov, Lawrence True, Toyonori Tsuzuki, Jennifer Turner, Theo van der Kwast, Mark Weiss, Thomas Wheeler, Kirk Wojno, Keith Volmar, Chin-Lee Wu, Jorge Yao, Asli Yilmaz and Jim Zhai. 